\title{
Partnering with Students in Iceland and Continental Europe to Develop a New Undergraduate Microbiology Research Journal
}

\begin{abstract}
Fine Focus - an interdisciplinary, product-based course-has involved 12 to 24 undergraduates each semester since 2013. This course developed and manages the first international digital and print journal for undergraduate microbiology research, with the American Society for Microbiology (ASM) as a partner. The course's student review team makes decisions that direct the future of the journal, including the double-blind peer-review system; the marketing/graphics team determines the best targeting of Fine Focus to a global audience; and undergraduates in Iceland recently participated to pilot this learning model in a different educational climate, enhancing the home university's international profile at the same time. The author discusses how these students gained a comprehensive understanding of working with others across disciplines in a professional atmosphere, creating a respected and tangible product that contributes to the undergraduate microbiology research community, and publishing their microbiology research. This faculty-led, student-driven "immersive learning" model allows the students to be the authors of, and authorities on, their own education.
\end{abstract}

Keywords: course-based research, immersive learning, interdisciplinary, microbiology, scholarly publishing

Overview of Teaching Model: The "What, How, and Why"

Development of creative student-centered research into existing biology curricula is a major theme of the recent AAAS Call to Action (Brewer and Smith 2011), as is "community-based participatory research." Ball State University can take advantage of many of these rapidly evolving objectives in undergraduate science education largely through its Biotechnology Certificate Program, an active chapter of Sigma $\mathrm{Xi}$, and the first ASM chapter in Indiana (McKillip 2010). Building on these opportunities, editorial board experiences with disciplinary journals, and 15 years of mentoring microbiology undergraduates, the author-a Ball State faculty member-decided to develop a product-based course to pilot that would fit the university's definition of "immersive learning." The end product would be the first undergraduate journal for microbiology research published in both print and digital versions. However, this course would possess most of the defined characteristics of immersive learning (Pagano 2013):
- Carry academic credit

- Engage participants in an active learning process that is student-driven but guided by a faculty mentor

- Produce a tangible outcome or product, such as a business plan, policy recommendation, book, play, or DVD

- Involve a team of students, often working on a project that is interdisciplinary in nature

- Include a community partner(s) and create an impact on the larger community as well as on the student participants

- Focus on student learning outcomes

- Help students define a career path or connect to a profession or industry

In short, Fine Focus is a faculty-led, student-driven, product-oriented course offered each semester under a variety of departmental credits, including honors, practicum, special topics, and related hours.

For some time, it has been clear that undergraduates need to be trained on the aspects of doing science that follow the completion of their laboratory bench work, fieldwork, and data analyses. Such experiences include acquisition of a working knowledge on scientific writing, editing, peer review, graphic design, and marketing, as they relate to dissemination of microbiological research data through an academic journal with international scope. Because many undergraduate science curricula do not thoroughly teach these skills, students are not fully equipped to become faculty members, industry scientists, peer reviewers, or editors. Undergraduate students also need to graduate with established, permanent, professional contacts in varied subdisciplines of microbiology worldwide. Addressing these needs through a product-based course would entail multifaceted aspects of both teaching and research.

For the development of the course at the home institution and implementation in Iceland, the dynamic was designed carefully. The students are empowered to develop ownership on the products of their labor-to share in the vision. This professional and personal investment of time and interest stems from direct engagement of the students at all levels of 
the journal's development and dissemination. Three teams of students are typically assigned each semester. First, a review team composed of four to five students in the life sciences (typically pre-med, microbiology, or zoology majors) are taught to coordinate a two-tiered review process. These students secure and manage incoming manuscript submissions to two or more outside reviewers (faculty or industry contacts at other institutions who serve on the Fine Focus editorial board) as well as participate in a simultaneous in-house review of the submissions. Second, a graphics team composed of four to five students (typically communications, graphics, and/or computer science majors) spearhead the effort of preparing proofs for corresponding authors and assembling the final papers into bound print journals for dissemination to those who subscribe. These students also manage the electronic version of Fine Focus, including the ancillary aspects of the associated website. Third, a marketing team of four to five students explores avenues for perpetuating the journal beyond the internal grant-supported funding period. For example, this team from marketing and management secures sponsorship from vendors and arranges advertising. This role involves travel to regional and national scientific conferences, such as the American Society for Microbiology (ASM) and the National Conference on Undergraduate Research (NCUR), to stimulate interest and solicit manuscript submissions.

By the time of the Iceland experience, Fine Focus was in its third year and thus had evolved to the point where it could be successfully managed by a slightly smaller group of students, but in Iceland these individuals still represented disciplines and worked in teams. Class days (approximately four hours each week of contact time) were spent clarifying weekly action items and objectives, providing instruction on scientific writing (via Lindsay 2011), hosting guest speakers in specialty areas, and presenting team progress reports.

\section{Implementation (the "Where")}

Founded in 1987, the University of Akureyri (UnAk) is a vibrant university on the north coast of Iceland with small but steadily increasing enrollments in biotechnology-related courses, including microbiology. Faculty at UnAk actively engage with undergraduate students in a variety of research projects. Some of these faculty members had served as coauthors on several grant proposals of the author, providing a foundation for future collaboration. In October 2013 the author traveled to UnAk as a seminar presenter and guest lecturer for a biotechnology/microbiology course, where he met with faculty and undergraduate students in this discipline. These meetings led to the conclusion that a course such as Fine Focus would provide a unique professional development opportunity for an array of students (they ultimately came from the Czech Republic, Finland, Iceland, and the United States). Students were recruited by the author, an Icelandic colleague, and the UnAk international students' office. By enrolling this diverse group of students (see Figure 1), it was hoped that the profile of Fine Focus could be raised in Iceland and the rest of Europe and result in increased submission of undergraduate research manuscripts. However, a number of other course objectives were added for these students, such as the following:

- Initiating a crowdfunding site for Fine Focus (http://www. firstgiving.com/fundraiser/johnl-mckillip/FineFocus/)

- Applying for an ISSN and working to place Fine Focus in searchable scientific databases, including EBSCOhost.

- Managing incoming manuscripts

- Increasing the size of the editorial board (to approximately 75 individuals)

- Cultivating closer partnerships with ASM, NIH, Sigma Xi, and/or the Council on Undergraduate Research (CUR)

Regarding assessment, students involved in Fine Focus come away with a working knowledge of three fundamental concepts:

- How to organize people and resources essential for academic and fiscal success of a start-up research journal,

- How to effectively critique scientific writing and communicate assessments to corresponding authors-a vital skill in many disciplines, and

- How to blend creativity (in overall design and marketing of the journal) with the objective guidelines that govern proper scientific experimental design and strict manuscript format.

\section{Figure 1. Fine Focus Biotechnology Students at the University of Akureyri in Iceland Complete an Internal Peer Review for Comparison to Comments by Outside Experts from the Double-blind Review Process}

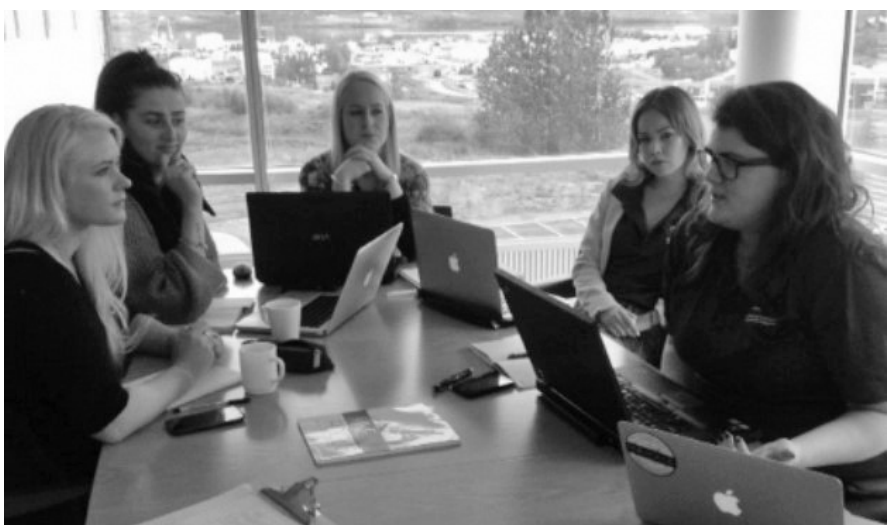


Journals are kept by each student as a daily log of responsibilities, objectives, and outcomes. Weekly roundtable sessions with the students identify problems encountered and questions, discuss possible solutions, and formulate decisions that are voted on by the students. This approach reinforces the idea that the journal's success is based on student input. In addition, weekly meetings with each student provide a venue for discussing matters impractical in a group setting. Student grades are compiled partially by students grading the others, including themselves (which occurs at midterm and at the end of the semester). These grades are submitted to the faculty member without any students seeing each other's evaluations. The faculty member assimilates these scores and compares them generally with his overall subjective rank on each student's performance. The student journals and self-assessments determine an overall final course grade for each student.

In addition, an assessment rubric designed for immersive learning courses at Ball State (https://cms.bsu.edu//media/ www/departmentalcontent/immersivelearning/pdfs/provost_grant_assessment_tool_example.pdf?la=en) may assist in gathering quantitative data on the overall impact of Fine Focus. Its metrics might be applied to the degree of collaboration among the team(s) of students, involvement of community partners, quality of the product generated, and completion of key course objectives. This rubric, as well as a consumer survey completed by fall 2016 students, will allow measuring of defined ways that the digital and print journal can offer improved content, quality, and aesthetics for prospective authors, editorial board members, and other collaborators.

The semester in Iceland managing Fine Focus was likely the most productive and positive term to date in terms of accomplishments, some of them unexpected opportunities upon which the students could capitalize. Collaboration between students at the home and host institutions came about naturally. The digital proofs were copyedited multiple times, and a great deal of correspondence ensued between the Icelandic review team and the graphics team and printer in Indiana. This exchange allowed the Icelandic students to hone their skills in English.

One additional highlight was the chance for Finnish exchange student Saara-Maria Helena Kallio (an international marketing major) to present at the British Conference of Undergraduate Research (BCUR) in March 2016 in Manchester, UK (see Figure 2). This professional development opportunity was the perfect capstone experience for Kallio. She was able to network and promote Fine Focus to a new audience by distributing logo-emblazoned polo shirts, print copies of the latest issue, and other promotional information. This experience proved key to Kallio's obtaining a business internship in Germany during summer 2016. Kallio's many emails during and following BCUR revealed that this experience was one of the most professionally meaningful and rewarding ones for her and certainly one that positively affected Fine Focus. The current group of Fine Focus students have once again brought Kallio into a collaboration by inviting her to be a founding member of the executive committee, which will plan for long-term success of Fine Focus as a journal and as a course. The first executive committee meeting is tentatively planned for autumn 2017 and will involve four to five individuals in marketing, graphics, and microbiology representing a diversity of content knowledge, geographical background, and journal/technical writing experiences.

\section{Challenges and Adaptation}

English is a principal language spoken in Iceland and is the universal language of science. Even though no language proficiency requirements are in effect for this location, the author worked to become fluent in Icelandic to facilitate communication between students and colleagues. Professional development opportunities such as Fine Focus are the universal conduit

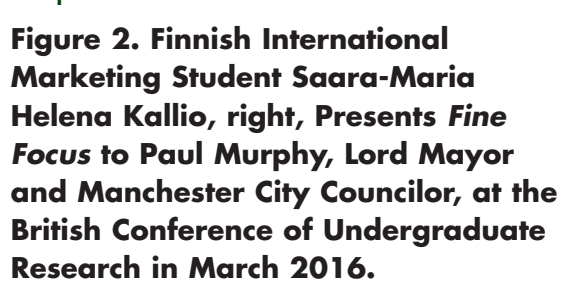

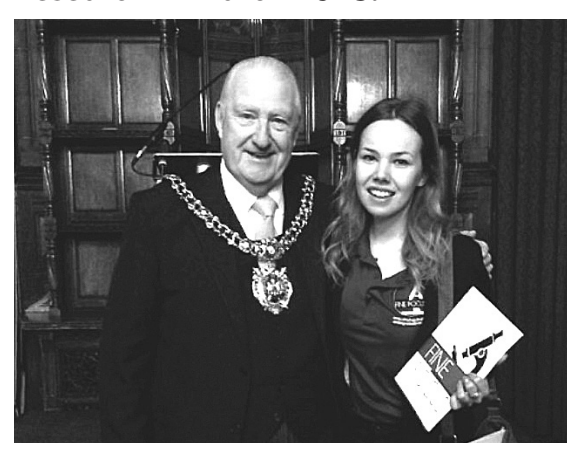
for success in scientific disciplines. Thus, implementation of this course at UnAk differed in only a few fundamental ways from how it is done at the home institution. First, the culture of Iceland is deeply rooted in its Scandinavian heritage and history, regardless of an individual's career path or level of education. As such, the approach to managing this course involved a much more active dialogue and exchange of personal ideologies than usually used by the faculty member. Significant time was spent getting to know each student and becoming acquainted with their personal and professional backgrounds as well as their career visions, so that the cultural divide could be bridged, and free and open communication could be fostered.

Second, the smaller class size (eight students) at UnAk was a stark contrast to most of the content courses at the home institution. However, this more readily cultivated positive, small-group dynamics and the team approach implemented for Fine Focus. The smaller size also facilitated continually evolving marketing/promotion activities and manuscript management. 
Last, the interdisciplinary nature of Fine Focus necessitated students with backgrounds/interests in marketing/advertising, graphic arts, and microbiology. Such broad student backgrounds required a proactive recruiting effort initiated well before the author's arrival at UnAk, facilitated by an UnAk colleague who advertised the course, objectives, and broad goals. The resulting internationally diverse group of motivated students was a pleasant surprise, considering the fact that they had enrolled with little knowledge of the big picture of the course, the teaching model of the course, and the journal.

Funding was, and is, an ongoing challenge. The principal costs of perpetuating Fine Focus are printing costs and student travel. Since Fine Focus does not have page charges, submission fees, or subscription revenue, the operating costs must originate from grant support, funding from private foundations, and donations. Relatively few federal grant opportunities are geared toward this product-based learning model, and even fewer private foundations offer funding possibilities for science education or scholarly engagement beyond $\mathrm{K}-12$. The FirstGiving site should offer some assistance in this regard, but continued growth will require creative and nontraditional outreach to obtain sponsorship by additional community partners and professional societies.

\section{Broad Impact and Future Growth (Evolution)}

Fine Focus offers transfer and adaptation possibilities for other institutions. Because the need for greater information literacy and technical writing skills is universal, the target student pool is ubiquitous. Although implementation of such a course would depend on the infrastructure of a particular college or university, establishing a collaborative network of professionals is certainly necessary. Many activities of the Fine Focus students may involve expertise well outside of a faculty member's comfort zone. However, with departmental/college/provost funding, outside speakers can be engaged, offering roundtables and forum sessions vital for student connections to professionals outside of the home institution. The Fine Focus faculty member and students have hosted and traveled to visit editors-in-chief as well as experts on marketing, printing, assessment, and science education/service learning. Reflecting student leadership and the tendency of these experts to be much more responsive to student rather than faculty inquiries, the students extend the invitations, handle the logistics of visits, and manage the dialogue during guest speaker days. This approach works because all participants share the broad vision of the student-generated, faculty-led model.

Other aspects of Fine Focus offer resources to the undergraduate research community. First, the journal's instructions to authors is a succinct and clear set of guidelines for prospective undergraduate authors anywhere, regardless of the particular journal target for their manuscript. In addition, posted on the Fine Focus website (http://www.finefocus.org), are two tutorial videos on preparation and presentation of figures, tables, and legends for professional publications. Second, the marketing teams have developed a comprehensive style guide encompassing color, paper, formatting, logo, and printing criteria for print and digital journal production. Third, a new custom template is in development for Overleaf ${ }^{\mathrm{TM}}$ that should facilitate and streamline manuscript submission formatting in the future.

The Iceland semester for Fine Focus led to a larger pool of potential reviewers, editorial board members, and international manuscript submissions. Because of this success, an executive committee can be established that will oversee strategic planning decisions. Like the editorial board, this committee will be international in composition and diverse in content knowledge. This latest development builds on the Fine Focus experience as an immersive learning course benefiting students at home and host institutions and as an open-access undergraduate microbiology research journal. Through close association with professional societies such as ASM and CUR, a constant flow is ensured of fresh ideas, energy, and original manuscripts that reflect the work of undergraduates in the international community of microbiology and science education.

\section{References}

Brewer, Carol, and Diane Smith (Eds). 2011. Vision and Change. Accessed June 1, 2016. http://visionandchange.org/files/2013/11/aaas-VISchange-web1113. pdf.

Lindsay, David. 2011. Scientific Writing: Thinking in Words. Collingwood, Australia: CSIRO Publishing. doi: 10.5860/choice.49-0230.

McKillip, John L. 2010. "Transformative Undergraduate Research: Students as the Authors of and Authorities on Their Own Education." CUR Quarterly 30(2): 10-15.

Pagano, Koreen. 2013. Immersive Learning: Designing for Authentic Practice. Alexandria, VA: ASTD Press.

\section{John McKillip}

Ball State University, jlmckillip@bsu.edu

John McKillip is associate professor in the Department of Biology at Ball State University and serves as a CUR Councilor for the Biology Division. He earned a PhD in microbiology from Washington State University in 1997 and completed a postdoc at Mississippi State University in 1999. His research program centers on molecular food safety/bacterial detection using DNA and RNA-based methods. Since 2009, McKillip has served on the editorial boards for the Journal of Food Protection and the Journal of Dairy Science, most recently as a section editor and senior editor for JDS.

\section{doi: $10.18833 /$ curq/37/3/13}

